\title{
Proactive Scheduling of Hydrogen Systems for Resilience Enhancement of Distribution Networks
}

\author{
Hamed Haggi \\ Department of Electrical and \\ Computer Engineering \\ University of Central Florida \\ Orlando, Florida, USA \\ hamed.haggi@knights.ucf.edu
}

\author{
Wei Sun \\ Department of Electrical and \\ Computer Engineering \\ University of Central Florida \\ Orlando, Florida, USA \\ sun@ucf.edu
}

\author{
James M. Fenton \\ Florida Solar Energy \\ Center \\ University of Central Florida \\ Cocoa, Florida, USA \\ JFenton@fsec.ucf.edu
}

\author{
Paul Brooker \\ Orlando Utilities Commission \\ Orlando, Florida, USA \\ PBrooker@ouc.com
}

\begin{abstract}
Recent advances in smart grid technologies bring opportunities to better control the modern and complex power grids with renewable integration. The operation of power systems, especially distribution network (DN), is facing with preeminent challenges from cyber-physical-human (CPH) threats and natural disasters. In order to provide better response against threats and improve the resilience of power grid, proactive plans and operational schemes are required by system operators to minimize the damages caused by CPH threats. To that end, this paper proposes a proactive plan for DN operation by using hydrogen (H2) systems to enhance the resilience through costeffective long-term energy storage. Unlike batteries, $\mathrm{H} 2$ energy can be stored in the storage tanks days before the extreme event, and transformed into power by fuel cell units in the postevent time to reduce load curtailment caused by CPH threats. The proposed framework is validated by testing on 33-node test feeder. Simulation results demonstrate that $\mathrm{H} 2$ systems can improve the resilience of DN during $N-m$ outages lasting for more than 10 hours.
\end{abstract}

Index Terms-Distributed energy resources (DERs), Distribution Network, Hydrogen Systems, Proactive Scheduling, Resilience Improvement.

\section{INTRODUCTION}

Recently, due to the large deployment of distributed energy resources (DERs) and other smart grid technologies, power systems are becoming more complex and vulnerable to extreme events. These extreme events can significantly affect the operation of power systems and results in outages and even cascading failures [1]. For instance, Hurricane Sandy (October 22-November 2, 2012) affected 7.5 million electricity consumers (mainly on the distribution side) with $\$ 65$ billion in damage [2]. Another example is the extreme cold temperature in the state of Texas (February 2021) affected the social and economic welfare of 4.5 million consumers [3]. To learn from the past events, utilities must pay extra attention to the resilience enhancement plans before the events. The promising strategies that the distribution system operator (DSO) can take to improve the resilience of distribution network (DN) include, 1) utilizing DERs to provide back up energy for serving local or critical loads; 2) damage preventive actions or system hardening; and 3) automation technologies to enhance the responsiveness to outages, etc. [4].
Recent research works have been focused on various aspects of resilience enhancement, such as proactive energy management, survivability analysis, and restoration actions. Since this paper is only focused on proactive scheduling as well as survivability analysis, restoration papers are not reviewed. However, interested readers are encouraged to refer to our previous work of reviewing recent advances in smart grid restoration [4]. Authors of [5] proposed a preparatory operation scheme for resilience enhancement of critical loads in automated DN. The framework was modeled as a stochastic optimization program considering pre- and post-event actions. A proactive operation scheme was proposed in [6] considering battery energy storage while addressing the uncertainty of load and renewable generation. In [2], a two-stage adaptive robust framework for resilience improvement with microgrids was proposed. A proactive scheduling considering the benefits of microgrid for resilience enhancement against windstorms was presented in [7]. The proposed method considered conservation voltage reduction, optimal parameter settings of droop controlled units and reconfiguration.

As mentioned above, proactive management of DERs can enhance the resilience of power systems. Recently, hydrogen (H2) energy has gained a lot of attention and has demonstrated a great potential for large-scale and long-duration energy storage deployment in the near future because of its economic, environmental, and technical merits. For more information regarding the $\mathrm{H} 2$ energy safety, interested readers are encouraged to see [8]. Unlike batteries which can only store/discharge energy for 4-8 hours with its maximum power and energy rating, $\mathrm{H} 2$ storage can store/discharge with maximum discharging capability for longer period of time (e.g. days and months). Research works in the literature are mainly focused on the normal operation of $\mathrm{H} 2$ systems and market mechanisms for $\mathrm{H} 2$ trading. For instance, a supervisory scheduling of $\mathrm{H} 2$ refueling stations considering the operating reserve signals was proposed in [9]. An optimal scheduling of $\mathrm{H} 2$ refuelling stations with the aim of fuel supply and capacitybased demand response for electrolyzers was analyzed in [10]. A decentralized local market for electricity and $\mathrm{H} 2$ trading based on game theory was proposed in [11] by considering the privacy of agents. An optimal energy management framework 
was proposed in [12] considering $\mathrm{H} 2$ energy as a fuel for proton exchange membrane fuel cell (FC) units. In this paper, $\mathrm{H} 2$ energy can be transformed to power with $\mathrm{FC}$ units and assist the grid in supplying the electric and thermal load.

Proactive scheduling as well as survivability analysis considering $\mathrm{H} 2$ systems to improve the DN resilience have not been fully investigated yet. Additionally, since the DSO is not the owner of all assets in DN, proper models are required for sending signals to $\mathrm{H} 2$ system owners in order to get prepared for emergency operations. To that end, the major contribution of this work is the proactive scheduling (pre-event analysis) and survivability analysis (post-event analysis) of $\mathrm{H} 2$ systems to improve the DN resilience. Prior to disruptions (e.g. days before), DSO sends signals to $\mathrm{H} 2$ system owners and asks them to completely fill their storage tank. This results in maximizing the survivability by using the stored $\mathrm{H} 2$ for stationary FC consumption and consequently the resilience improvement. Additionally, deploying long-term $\mathrm{H} 2$ storage results in lower cycling of DGs which increases the operational life of DGs and improves the resilience of these assets in the long term.

The rest of the paper is organized as follows. The problem formulation is introduced in Section III simulation results are presented in Section III] and Section IV concludes the paper.

\section{Problem Formulation}

The mathematical formulation of proactive scheduling of $\mathrm{H} 2$ systems in active distribution networks is presented in this section. The proposed model is formulated as a resilience constrained program (RCP) to address both proactive scheduling and survivability analysis. Given a $\mathrm{DN},(N, l)$, where $N$ and $l$ are the set of nodes and lines, the root node is shown as 0 , and $T$ represents the set of time steps indexed by $t$.

\section{A. Objective Function}

The objective function of the model is to minimize total operation cost of DN throughout the entire period of $T$ which can address both normal and emergency operation of DN.

$$
\begin{aligned}
\min . & \sum_{t=1}^{T}\left\{\rho_{t} P_{t}^{S T}+\sum_{i=1}^{N_{G}} C_{i, t}^{D G}+\sum_{i=1}^{N_{G}} C_{i, t}^{S U}+\sum_{i=1}^{N_{G}} C_{i, t}^{S D}\right. \\
& \left.+\sum_{i=1}^{N_{P V}} C_{i, t}^{P V}+\sum_{i=1}^{N} C_{i, t}^{S h d}\right\}
\end{aligned}
$$

where the first term refers to the cost of purchasing power from upper grid with the price of $\rho_{t}$. The second, third, and forth terms refer to the operational cost of utility operated power plants, start up and shutdown costs, respectively. The last two cost terms refer to the cost of utility operated PV units and load curtailment, respectively. It should be noted that the costs associated with $\mathrm{H} 2$ systems are not taken into account and DSO only schedules its system demand. In this paper, both DSO and H2 system owners perform the cost benefit analysis separately and exchange energy with power purchase agreement price [13].

\section{B. Technical Constraints and Models}

The aforementioned objective function is subjected to the following operational constraints for DGs, PVs, and $\mathrm{H} 2$ systems including electrolyzer, storage tank and stationary FC units.

1) Operational Constraints for DG Units: Let $x_{i, t}^{D G}, P_{i, t}^{D G}$, $Q_{i, t}^{D G}, b^{D G}, k^{D G}$, and $C_{i, t}^{D G}$ denote to the status, active power, reactive power, fixed operation and maintenance cost, ramping cost, and operational cost of DGs, respectively. Constraint (2) consists of two terms, fixed operation cost and ramping cost of DGs. Constraints (3)-(5) show the active and reactive power production limits. Startup cost of DGs, $C_{i, t}^{S U}$, as well as their shutdown cost, $C_{i, t}^{S D}$, are expressed in (6)- 9 [14]. Moreover, the ramp rate limits of DG are shown in (10), which $R_{i}^{D}$ and $R_{i}^{U}$ show ramp-down and ramp-up limits, respectively [15].

$$
\begin{gathered}
C_{i, t}^{D G}=x_{i, t}^{D G} \cdot b^{D G}+k^{D G} \cdot P_{i, t}^{D G} \\
P_{i, t}^{D G, m i n} \cdot x_{i, t}^{D G} \leq P_{i, t}^{D G} \leq P_{i, t}^{D G, \max } \cdot x_{i, t}^{D G} \\
Q_{i, t}^{D G, m i n} \cdot x_{i, t}^{D G} \leq Q_{i, t}^{D G} \leq Q_{i, t}^{D G, \max } \cdot x_{i, t}^{D G} \\
\left(P_{i, t}^{D G}\right)^{2}+\left(Q_{i, t}^{D G}\right)^{2} \leq\left(S^{D G}\right)^{2} \\
C_{i, t}^{S U} \geq\left(x_{i, t}^{D G}-x_{i, t-1}^{D G}\right) \cdot \rho^{S U} \\
C_{i, t}^{S U} \geq 0 \\
C_{i, t}^{S D} \geq\left(x_{i, t-1}^{D G}-x_{i, t}^{D G}\right) \cdot \rho^{S D} \\
C_{i, t}^{S D} \geq 0 \\
-R_{i}^{D} \leq P_{i, t}^{D G}-P_{i, t-1}^{D G} \leq R_{i}^{U}
\end{gathered}
$$

It is worth mentioning that other constraints such as minimum uptime and minimum downtime of DGs can be considered based on [15] to have more realistic results due to system inflexibility caused by DGs in some hours, which increases the total operation cost. To address this inflexibility, large scale $\mathrm{H} 2$ systems can be considered to reduce the total cost.

2) Operational Constraints for PVs and Substation Node: The operational cost of PV units, $C_{i, t}^{P V}$, is expressed in 11 . $P_{i, t}^{P V}$ and $Q_{i, t}^{P V}$ are denoted as active and reactive power of PV units, and their limits are expressed in (12) and (13) [16]. More information regarding the smart PV inverters and their role on resilience enhancement can be referred to [17] [18]. Additionally, the active and reactive power purchased from upper grid, $P_{i, t}^{S T}$ and $Q_{i, t}^{S T}$, are constrained by (14).

$$
\begin{gathered}
C_{i, t}^{P V}=c^{P V} \cdot P_{i, t}^{P V} \\
0 \leq P_{i, t}^{P V} \leq P^{P V, \max } \\
\left(P_{i, t}^{P V}\right)^{2}+\left(Q_{i, t}^{P V}\right)^{2} \leq\left(S^{P V}\right)^{2} \\
\left(P_{i, t}^{S T}\right)^{2}+\left(Q_{i, t}^{S T}\right)^{2} \leq\left(S^{S T}\right)^{2}
\end{gathered}
$$


3) Operational Constraints for H2 System: The operational constraints for $\mathrm{H} 2$ systems including electrolyzers, storage tank, and stationary FC units are expressed in (15)-21. Let us denote $P_{i, t}^{E L}, P_{i, t}^{F C}, Q_{i, t}^{E L}$, and $Q_{i, t}^{F C}$ to electrolyzer power, FC power, amount of $\mathrm{H} 2$ consumed by electrolyzer, and generated power by FC units, respectively. Constraints (15) and 16 show the amount of $\mathrm{H} 2$ produced or consumed by electrolyzers or FCs, based on efficiency $\eta$, power to $\mathrm{H} 2 \lambda^{E L}, \mathrm{H} 2$ to power $\lambda^{F C}$, and converting factors $[9]-[10]$. Constraints 177 and (18) present the limits for $\mathrm{H} 2$ production and consumption, based on the capacity limit of electrolyzers and FC units. Additionally, these constraints prevent the simultaneous operation of electrolyzer and $\mathrm{FC}$ units by considering a binary variable $\psi_{i, t}^{H S} . M O H_{i, t}^{H 2}$ denotes to the mass of $\mathrm{H} 2$ in storage tank, and dynamic $\mathrm{H} 2$ mass constraints are presented in (19) and (20). It should be noted that $Q_{i, t}^{d e m}$ and $\lambda^{D s p}$ are $\mathrm{H} 2$ demand from fuel cell electric vehicles (FCEVs) and $\mathrm{H} 2$ storage dissipation rate. In the case of $N-m$ disruptions, $\mathrm{H} 2$ systems can act as long-term energy storage with long-duration times compared to batteries. To that end, constraint 211) express the demand response (DR) signal, in which $\alpha_{t}$ denotes the percentage of $\mathrm{H} 2$ required as a reserve before emergency operation, from DSO regarding the $\mathrm{H} 2$ mass in the tank. Prior to any forecasted disruption $\left(t<t_{\text {event }}\right)$, DSO asks $\mathrm{H} 2$ system owners to fill their tank completely as a backup generation unit for supplying the load in the post-event time $\left(t \geq t_{\text {event }}\right)$. This will help the DSO to minimize the total cost and total load curtailment during the $N-m$ contingencies. Moreover, constraint (22) expresses the $\mathrm{H} 2$ systems inverter for voltage control.

$$
\begin{gathered}
Q_{i, t}^{E L}=\lambda^{E L} \cdot P_{i, t}^{E L} \cdot \eta^{E L} \\
P_{i, t}^{F C}=\lambda^{F C} \cdot Q_{i, t}^{F C} \cdot \eta^{F C} \\
Q^{E L, m i n} \cdot \psi_{i, t}^{H S} \leq Q_{i, t}^{E L} \leq Q^{E L, m a x} \cdot \psi_{i, t}^{H S} \\
Q^{F C, m i n} \cdot\left(1-\psi_{i, t}^{H S}\right) \leq Q_{i, t}^{F C} \leq Q^{F C, m a x} \cdot\left(1-\psi_{i, t}^{H S}\right) \\
M O H_{i, t}^{H 2}=M O H_{i, t-1}^{H 2}+\left(Q_{i, t}^{E L}-Q_{i, t}^{d e m}-Q_{i, t}^{F C}\right. \\
\left.\left.-\lambda^{D s p} \cdot M O H_{i, t}^{H 2}\right)\right) \cdot \Delta t \\
M O H^{H 2, m i n} \leq M O H_{i, t}^{H 2} \leq M O H^{H 2, \text { max }} \\
\sum_{i=1}^{N_{H}} M O H_{i, t}^{H 2} \geq \alpha_{t} \cdot \sum_{i=1}^{N_{H}} M O H^{H 2, \max } \\
\left(P_{i, t}^{E L}-P_{i, t}^{F C}\right)^{2}+\left(Q_{i, t}^{H S}\right)^{2} \leq\left(S^{H S}\right)^{2}
\end{gathered}
$$

4) Distribution System Constraints: The AC power flow constraints of DN are shown in 77)-30, where $V_{i, t}, f_{i, t}^{p}$, and $f_{i, t}^{q}$ refer to the squared voltage magnitude, active and reactive power flow of lines, respectively. It should be noted that LinDistflow [19] [20] is adopted for modeling the radial distribution system. Constraints (7) and (24) express the relationship between voltage drop based on active and reactive power flow in the lines, and voltage limits for every node, respectively. Constraints (25) and (26) show the nodal active and reactive power balance. Constraint (27) expresses the line capacity

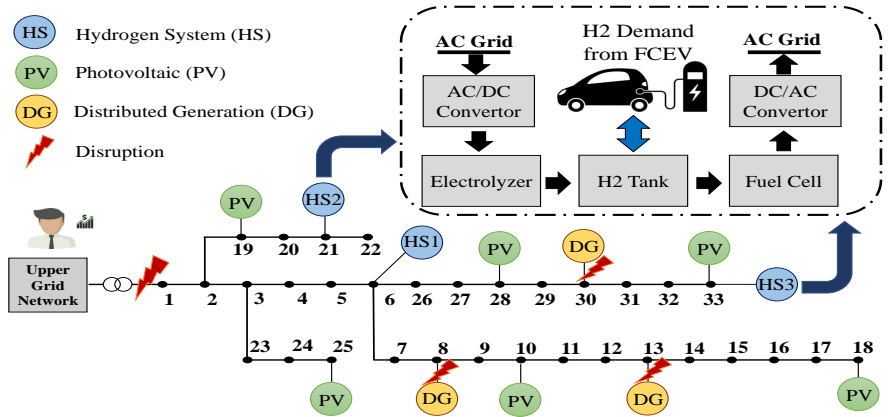

Fig. 1. Radial 33-node distribution test system with DERs.



Fig. 2. H2 demand from FCEVs

limit for active and reactive power flow. Constraint (28) shows the load curtailment cost in the emergency operation mode, which is penalized with the value of loss of load (VOLL), which is considered as $\$ 500 / \mathrm{MWh}$ in this paper. Finally, constraints (29) and (30) show the limits for load curtailment.

$$
\begin{gathered}
V_{i, t}=V_{j, t}-2\left(R_{j i} \cdot f_{i, t}^{p}-X_{j i} \cdot f_{i, t}^{q}\right) \\
\left(V^{\text {min }}\right)^{2} \leq V_{i, t} \leq\left(V^{\text {max }}\right)^{2} \\
f_{i, t}^{p}=P_{i, t}^{L o a d}+\sum_{j \rightarrow i} f_{j, t}^{p}+P_{i, t}^{E L}-P_{i, t}^{F C}-P_{i, t}^{P V}-P_{i, t}^{D G}-P_{i, t}^{S h d} \\
f_{i, t}^{q}=Q_{i, t}^{L o a d}+\sum_{j \rightarrow i} f_{j, t}^{q}+Q_{i, t}^{E L}-Q_{i, t}^{F C}-Q_{i, t}^{P V}-Q_{i, t}^{D G}-Q_{i, t}^{\text {Shd }} \\
\left(f_{i, t}^{p}\right)^{2}+\left(f_{i, t}^{q}\right)^{2} \leq\left(S^{\text {line }}\right)^{2} \\
C_{i, t}^{\text {Shd }}=V O L L . P_{i, t}^{\text {Shd }} \\
0 \leq P_{i, t}^{\text {Shd }} \leq P_{i, t}^{\text {Load }} \\
Q_{i, t}^{\text {Shd }}=P_{i, t}^{\text {Shd }} \cdot \frac{Q_{i, t}^{\text {Load }}}{P_{i, t}^{\text {Load }}}
\end{gathered}
$$

\section{Simulation Results AND AnAlysis}

The proposed proactive scheduling of $\mathrm{H} 2$ systems is validated on 33-node DN [19] with an hourly time step for a week. The DN hosts three utility-operated DGs, located at nodes 8,13 , and 30 with capacity limits of $0.8 \mathrm{MW}, 2.4 \mathrm{MW}$, and $1 \mathrm{MW}$, respectively. DG 8 and DG 13 are considered as combined-cycle units, and DG 30 is considered as a combustion turbine unit. Additionally, six PV units and three $\mathrm{H} 2$ systems are hosted by the DN as depicted in Fig. 1. The 


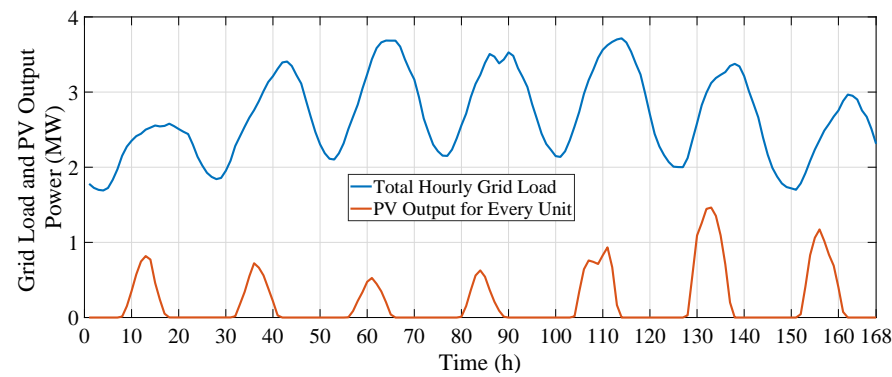

Fig. 3. Input data for grid load and output PV power.

TABLE I

PARAmeters Related To H2 Systems

\begin{tabular}{|c|c|c|c|}
\hline Parameter & Value & Parameter & Value \\
\hline$\eta_{E L}$ & $60 \%$ & $\eta_{F C}$ & $70 \%$ \\
\hline$P^{E L, \text { max }}$ & $3(\mathrm{MW})$ & $P^{E L, \text { min }}$ & $0(\mathrm{MW})$ \\
\hline$P^{F C, \text { max }}$ & $3(\mathrm{MW})$ & $P^{F C, \text { min }}$ & $0(\mathrm{MW})$ \\
\hline$M O H^{\max }$ & $600(\mathrm{~kg})$ & $M O H^{\text {min }}$ & $60(\mathrm{~kg})$ \\
\hline$\lambda_{D s p}$ & $0.006 \% \times M O H_{i, t}$ & Specific Energy & $56.4(\mathrm{kwh} / \mathrm{kg})$ \\
\hline
\end{tabular}

operational costs for generation units are based on [21] for year 2050. H2 demand from FCEVs is calculated based on the method presented in [22], with the assumption of $20 \%$ penetration level for year 2050. FCEVs are Honda Clarity models [23] assuming that these cars arrive at $\mathrm{H} 2$ stations with $45 \%$ fuel in their tank. In other words, FCEVs fill the tanks for the remaining 55\% tank capacity, as depicted in Fig. 2 Considering the extreme event scenario from generation perspective, it is assumed that the tie line between DN and upper grid as well as three DGs are out of service for almost two days (from hour 79 till 128). The optimization time horizon is one week with hourly time steps. The input data for load and every PV unit are shown in Fig. 3 Moreover, the penetration of $\mathrm{PV}$ units is increased by a factor of 2.5 yielding a solar penetration around $40 \%$. Finally, the parameters used for modeling the $\mathrm{H} 2$ systems are presented in table [1]

\section{A. Simulation Results for Proactive Scheduling of H2 Systems considering FCEVs Demand}

The results for proactive management $\left(t<t_{\text {event }}\right)$ and survivability ( $\left.t \geq t_{\text {event }}\right)$ are shown in Fig. 4 to Fig. 7 Fig. 4 shows the mass of $\mathrm{H} 2$ in the tank during the pre- and postevent times. It shows that based on the signal from DSO, all $\mathrm{H} 2$ systems must fill their storage tanks before the event time. As a result, at hour 79, all $\mathrm{H} 2$ systems' storage tanks are full. In addition, Fig. 5 shows the Electrolyzers consumed power prior to the event time to reach the maximum capacity of storage tank. It is also shown that most of the system load is supplied by FC units during hours 79 to 100 . Another critical indicator of reliable DN scheduling is voltage values, which the voltage magnitudes and average voltage values are shown in Fig. 6 and Fig. 7 respectively.

\section{B. Resilience Analysis for Different Case Studies}

In order to provide a fair comparison between FC units and battery storage systems, $\mathrm{H} 2$ demand is considered zero

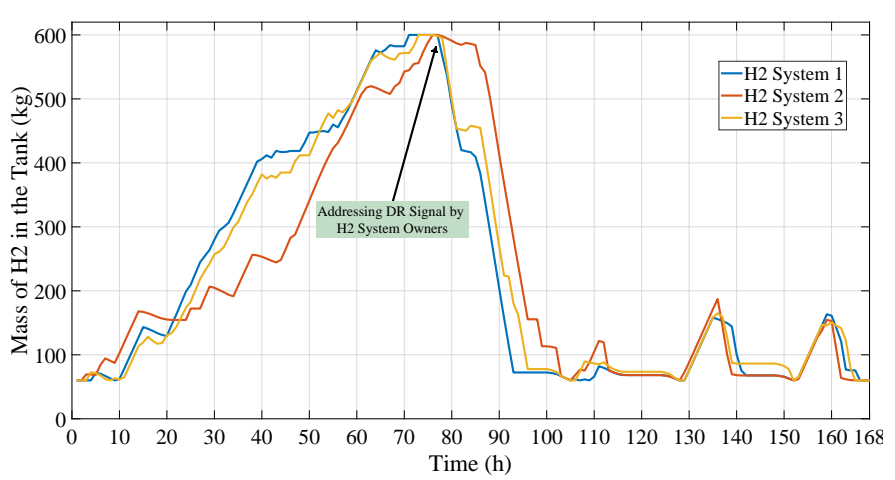

Fig. 4. Mass of $\mathrm{H} 2$ in the storage tank for $\mathrm{H} 2$ systems.

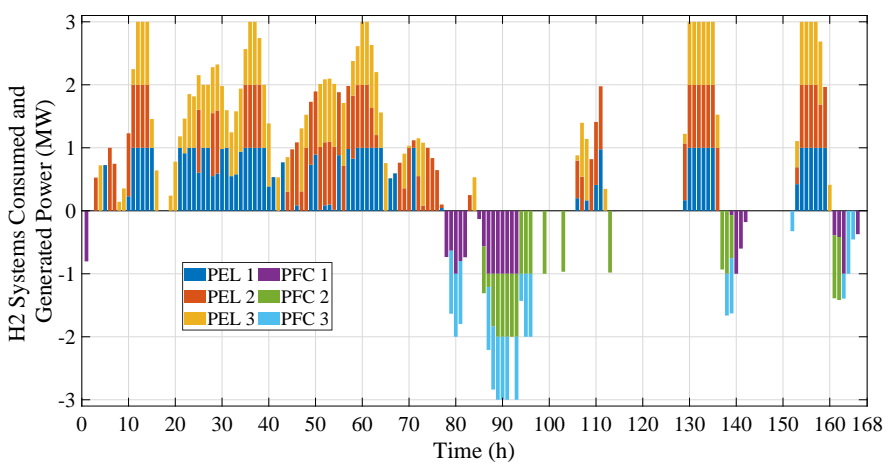

Fig. 5. H2 systems consumed and generated power.

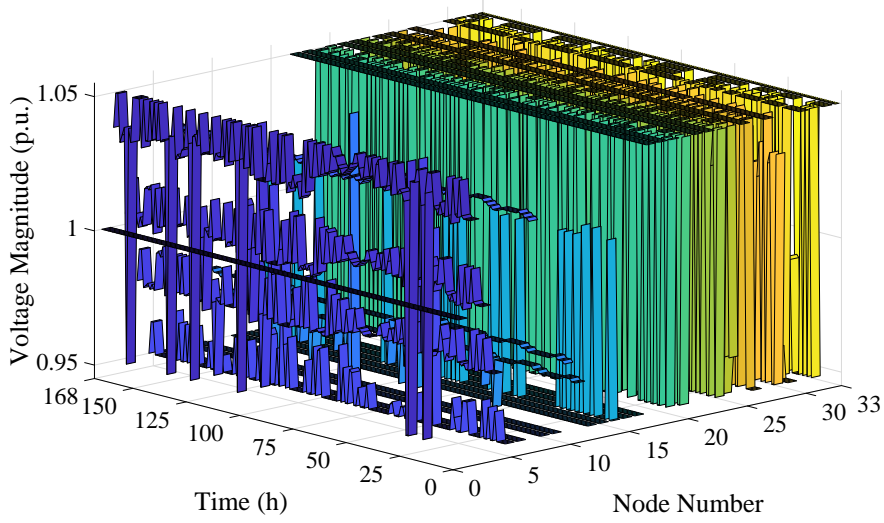

Fig. 6. Voltage values during the week.

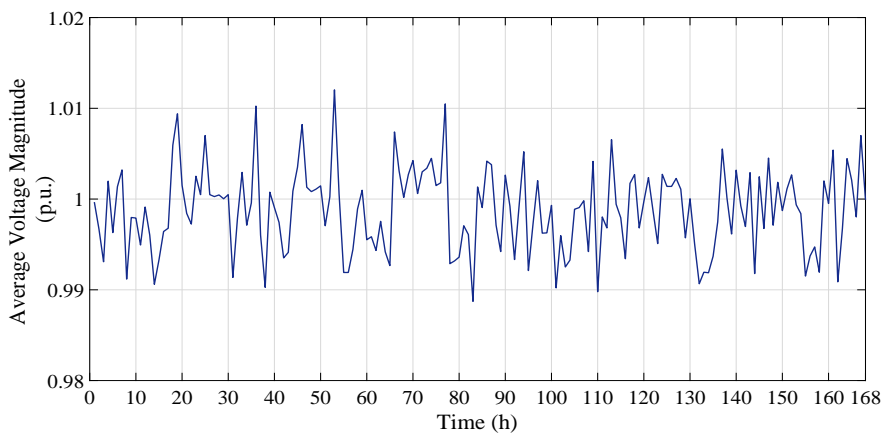

Fig. 7. Average voltage values during the week. 
TABLE II

Resilience ANALYsis FOR DifFERENT CASE StUdies

\begin{tabular}{|c|c|c|c|c|c|c|}
\hline Case Study & $\mathbf{1}$ & $\mathbf{2}$ & $\mathbf{3}$ & $\mathbf{4}$ & $\mathbf{5}$ & $\mathbf{6}$ \\
\hline $\begin{array}{c}\text { Energy Not Supplied } \\
\text { (MWh) }\end{array}$ & 101.9 & 91.8 & 85.3 & 79.8 & 75.6 & 52.0 \\
\hline $\begin{array}{c}\text { Resilience Index } \\
(\%)\end{array}$ & 77.4 & 79.6 & 81 & 82.3 & 83.2 & 89.2 \\
\hline
\end{tabular}

$\mathrm{kg}$. Additionally, the power rating of battery power rating is assumed to be equal to that of electrolyzer and FC units. To analyze the resilience of DN with proactive scheduling, six scenarios are considered in handling the out-of-service tie line between DN and upper grid, as well as the three DGs being out of service for almost two days (from hour 79 till 128) The first scenario is the base case without proactive scheduling; next four scenarios are the base case with battery of 2, 4, 6, 8 hours duration, respectively; and the last scenario is the base case with $\mathrm{H} 2$ systems including electrolyzer, tank, and stationary FC units. Table [I] shows the results of the unserved energy and the resilience index. It should be noted that resilience index (RI) used in this paper is defined as follows:

$$
R I(\%)=\left(\frac{\text { Total Load }- \text { Curtailed Load }}{\text { Total Load }}\right) \times 100
$$

Using the RI, it can be easily seen that maximum unserved energy happened in case 1 (worst scenario) and minimum unserved energy happened when $\mathrm{H} 2$ systems are used with stationary FC units as backup generation units. Additionally, higher RI values show that $\mathrm{H} 2$ systems can perform better compared to batteries with 2-8 hours duration time, which demonstrates the value for large deployment of these systems in the near future.

\section{CONCLUSion AND Future Work}

In this paper, a proactive scheduling of $\mathrm{H} 2$ systems in an active distribution network for resilience enhancement is proposed with the goal of minimizing operational cost and load curtailment. Unlike battery storage systems which can only store energy for 4-8 hours, H2 systems including electrolyzers, storage tanks, and FC units can store $\mathrm{H} 2$ energy for long duration. In the case of multiple DG and line outages for more than 10 hours, $\mathrm{H} 2$ system can significantly enhance the resilience of system by supplying the loads based on their storage tank and FC units. The future work will be the extension of proposed framework by 1) addressing DERs' uncertainty with robust techniques in unbalanced DNs; and 2) analyzing the impact of long-duration $\mathrm{H} 2$ storage in resilience enhancement of integrated transmission and distribution systems.

\section{ACKNOWLEDGMENTS}

This work is supported by U.S. Department of Energy's award under grant DE-EE0008851.

\section{REFERENCES}

[1] S. R. Khazeiynasab and J. Qi, "Resilience analysis and cascading failure modeling of power systems under extreme temperatures," Journal of Modern Power Systems and Clean Energy, 2020.
[2] A. Gholami, T. Shekari, and S. Grijalva, "Proactive management of microgrids for resiliency enhancement: An adaptive robust approach," IEEE Transactions on Sust. Energy, vol. 10, no. 1, pp. 470-480, 2017.

[3] DOE, "Extreme cold and winter damages in texas," [Online] https:// www.energy.gov Tech. Rep., 2021.

[4] H. Haggi, M. Song, W. Sun et al., "A review of smart grid restoration to enhance cyber-physical system resilience," in 2019 IEEE Innovative Smart Grid Technologies-Asia (ISGT Asia), 2019, pp. 4008-4013.

[5] H. T. Nguyen, J. Muhs, and M. Parvania, "Preparatory operation of automated distribution systems for resilience enhancement of critical loads," IEEE Transactions on Power Delivery, 2020.

[6] A. Hussain, V.-H. Bui, and H.-M. Kim, "A proactive and survivabilityconstrained operation strategy for enhancing resilience of microgrids using energy storage system," IEEE Access, vol. 6, pp. 75 495-75 507, 2018.

[7] M. Amirioun, F. Aminifar, and H. Lesani, "Resilience-oriented proactive management of microgrids against windstorms," IEEE Transactions on Power Systems, vol. 33, no. 4, pp. 4275-4284, 2017.

[8] N. Barilo, S. Weiner, and C. James, "Overview of the doe hydrogen safety, codes and standards program part 2: hydrogen and fuel cells: emphasizing safety to enable commercialization," International Journal of Hydrogen Energy, vol. 42, no. 11, pp. 7625-7632, 2017.

[9] H. Khani, N. A. El-Taweel, and H. E. Z. Farag, "Supervisory scheduling of storage-based hydrogen fueling stations for transportation sector and distributed operating reserve in electricity markets," IEEE Transactions on Industrial Informatics, vol. 16, no. 3, pp. 1529-1538, 2019.

[10] N. A. El-Taweel, H. Khani, and H. E. Farag, "Hydrogen storage optimal scheduling for fuel supply and capacity-based demand response program under dynamic hydrogen pricing," IEEE Transactions on Smart Grid, vol. 10, no. 4, pp. 4531-4542, 2018.

[11] Y. Xiao, X. Wang, P. Pinson, and X. Wang, "A local energy market for electricity and hydrogen," IEEE Transactions on Power Systems, vol. 33, no. 4, pp. 3898-3908, 2017.

[12] M. Rahmanzadeh, H. Haggi, and M. Aliakbar Golkar, "Optimal energy management of microgrid based on fcchp in the presence of electric and thermal loads considering energy storage systems," 2018.

[13] T. Shekari, S. Golshannavaz, and F. Aminifar, "Techno-economic collaboration of pev fleets in energy management of microgrids," IEEE Transactions on Power Systems, vol. 32, no. 5, pp. 3833-3841, 2016.

[14] A. Gholami, T. Shekari, F. Aminifar, and M. Shahidehpour, "Microgrid scheduling with uncertainty: The quest for resilience," IEEE Transactions on Smart Grid, vol. 7, no. 6, pp. 2849-2858, 2016.

[15] H. Haggi, F. Hasanzad, and M. Golkar, "Security-constrained unit commitment considering large-scale compressed air energy storage (caes) integrated with wind power generation," International Journal of Smart Electrical Engineering, vol. 6, no. 04, pp. 127-134, 2017.

[16] F. Rahmani, M. A. Robinson, and M. Barzegaran, "Cool roof coating impact on roof-mounted photovoltaic solar modules at texas green power microgrid," International Journal of Electrical Power \& Energy Systems, vol. 130, p. 106932, 2021

[17] A. Y. Fard and M. B. Shadmand, "Multitimescale three-tiered voltage control framework for dispersed smart inverters at the grid edge," IEEE Transactions on Industry Applications, vol. 57, no. 1, pp. 824-834, 2020.

[18] A. Y. Fard, M. B. Shadmand, and S. K. Mazumder, "Holistic multitimescale attack resilient control framework for power electronics dominated grid," in 2020 Resilience Week (RWS). IEEE, 2020, pp. 167-173.

[19] M. E. Baran and F. F. Wu, "Network reconfiguration in distribution systems for loss reduction and load balancing," IEEE Power Engineering Review, vol. 9, no. 4, pp. 101-102, 1989.

[20] A. Taghavirashidizadeh, R. Parsibenehkohal, M. Hayerikhiyavi, and M. Zahedi, "A genetic algorithm for multi-objective reconfiguration of balanced and unbalanced distribution systems in fuzzy framework," Journal of Critical Reviews, vol. 7, no. 7, pp. 639-343, 2020.

[21] L. J. Vimmerstedt, C. R. Augustine, P. C. Beiter, W. J. Cole, D. J. Feldman, P. Kurup, E. J. Lantz, R. M. Margolis, T. J. Stehly, C. S. Turchi et al., "2018 annual technology baseline (atb)," National Renewable Energy Lab.(NREL), Golden, CO (United States), Tech. Rep., 2018.

[22] W. Sun, N. Kadel, I. Alvarez-Fernandez, R. R. Nejad, and A. Golshani, "Optimal distribution system restoration using phevs," IET Smart Grid, vol. 2 , no. 1 , pp. 42-49, 2018.

[23] "Fuel cell electric vehicle data," [Online] https://www.fueleconomy.gov 